\title{
Una novela de Riva Palacio en entredicho
}

Leticia Algaba

UAM-AZCAPOTZALCO

A través de una réplica clerical a la novela Monja y casada, virgen y mártir se examina la recepción que tuvo en su tiempo la obra, el estatuto de la novela histórica y el de cierta crítica literaria.

ra novela. Incursiona en el género con una pluma bien experimentada en el periodismo, el drama y la coración de la república, cuando las palabras conciliar y renovar intentaban dar cimiento al proyecto de un nuevo Estado mexicano, el general Vicente Riva Palacio, ya entonces prominente liberal y una de las voces que solicitaba y ejercía la concordia, conmovido aún por la lucha de los chinacos-los soldados con quienes compartió el triunfo sobre las fuerzas del segundo imperio el 20 de junio de 1867-, escribe, basado en tal suceso, Calvario y Tabor, su primemedia, proveedores de muchos recursos, entre los cuales sobresale la relación, armónica y eficaz, con el lector. Las primeras páginas de la novela fueron leídas en una de las veladas literarias del mes de marzo de 1868. Los comentarios sobre la lectura destacaban la índole de la obra: "La primera en su género [...] Histórica y de costumbres [...] encierra hechos y descripciones que sólo pudo hacer quien, como su autor, ha visitado los lugares en que pasan los sucesos que rela- 
ta." ${ }^{2}$ La sugerencia para la publicación fue aceptada de inmediato; el 26 de marzo, el periódico La Orquesta da a conocer el prospecto, en el que de nuevo se resalta la calidad del autor como "testigo de los sucesos que refiere", por lo que "no podrá dudarse de su veracidad. Observador de las costumbres y de los paisajes que describe, nadie como él puede presentarlos al público con tan vivos colores". ${ }^{2}$ Así, Riva Palacio echará a andar un ejercicio narrativo a través de ocho novelas históricas que ven la luz pública sin descanso en el curso de cuatro años, de 1868 a 1872 , continuidad delatora de un plan cuyos trazos y realizaciones pondrán la historia y la ficción literaria en vasos comunicantes, de tal suerte que el novelista pronto se convertirá en historiador del periodo colonial para México a través de los siglos, una de las obras fundamentales de la historiografia mexicana que, además, estuvo bajo su dirección. ${ }^{3}$

De marzo a junio de 1868 , Riva Palacio cumple puntualmente con la escritura de las entregas de Calvario y Tabor, de igual modo que Manuel C. Villegas, el editor, las envía a numerosos suscriptores que fueron aumentando luego de las primeras entregas, pues a principios del mes de mayo se habían agotado seis mil ejemplares. Autor, editorylectores formaron pronto y con éxito una relación armónica,

${ }^{1}$ La Orquesta, 21 marzo 1868.

${ }^{2}$ La Orquesta, abril 1868.

3 José Ortiz Monasterio verifica en las novelas los primeros pasos del historiador. Historia, 1994. que abre el camino para la siguiente novela con el curioso título de Monja y casada, virgen y mártir, cuyo prospecto aparece en La Orquesta el 16 de junio y la destaca como "magnífica novela histórica y de costumbres, sacada de los archivos de la Inquisición" " ${ }^{4}$ Se ofrece al lector la seguridad de que el autor seguirá los mismos pasos del narrador de Calvario y Tabor, y que para la confección de la novela el autor "ha tenido que registrar las crónicas de otros tiempos". 5 En efecto, Riva Palacio escudriñaba documentos de la Inquisición, que serían fuente para las siete novelas sobre el pasado colonial, subsecuentes a Calvario y Tabor, la única que se refiere a hechos contemporáneos.

A mediados del mes de julio se publicó la primera entrega de Monja y casada... y se anunciaba que constará de 18 a 20, que las estampas se darán al término de la publicación, cuyo fin se garantiza. Al frente del periódico $L a$ Orquesta, aunque embozado en el nombre de Juan de Jarras, Riva Palacio, junto con Villegas, uno de sus editores, no cesaban de promover Monja y casada, virgen y mártir. Autor y editor registraban cuanta mención hacían de la novela otros periódicos; con ello, la reputación de ambos se acrecentaba, pues hubo elogios a la regularidad de las entregas y al bajo precio -un real cada una-, lo que satisfacía con creces la magnífica impresión en muy buen papel, marco digno de una preciosa novela, a decir de $L a O P i$ -

\footnotetext{
${ }^{4}$ La Orquesta, 18 junio 1868.

5 Ibid., p. 3.
} 
nión Nacional, que, además, advertía en el autor a un narrador capaz de graduar las expectativas del lector.

El 8 de septiembre, La Orquesta anunciaba que con la entrega número 20 concluiría la novela y, a la vez, insertaba el prospecto de Martín Garatuza, continuación de Monja y casada..., y en que se reiteraban iguales garantías: el autor ha abrevado en fuentes históricas de los tiempos pasados. Justo con el inicio del mes de diciembre, La Revista Universal publicaba sin firma de autor el artículo "Monja y casada, virgen y mártir. Breves observaciones sobre esta moderna novela" en la sección literaria del periódico. En contraste con su título, el artículo se alarga en numerosas entregas y termina hasta el mes de marzo de 1869 , con una periodicidad irregular de aproximadamente una $o$ dos veces por semana. Ciñéndose en principio al subtítulo de la novela: Memorias de la Inquisición, el autor discute la intención expresa de Riva Palacio por esclarecer ciertos sucesos de la colonia, especie de garantía que, según el crítico, la obra desmiente al tornarse en un instrumento para atacar a la institución eclesiástica.

A mediados de 1869 , los artículos formaban el volumen intitulado Bre. ves consideraciones sobre la moderna novela titulada "Monja y casada, virgen y mártir" (Historia de los tiempos de la Inquisición). Aceptación de un tremebundo reto, firmado con el pseudónimo de Alguien, publicación que seguramente intentaba divulgar a un público más amplio la descalificación de la novela y de los recursos de su autor, toda vez que la obra había te- nido muy buena acogida entre los lectores.

La tarea que asume José Mariano Dávila y Arrillaga, el verdadero nombre del crítico de Riva Palacio, es apenas una muestra de una obra signada por la combatividad: 81 años (nació en 1789 y murió en 1870), en los que mantuvo una relación muy estrecha con la Compañía de Jesús, a la que por los avatares de la orden, no pudo pertenecer enteramente. Su numerosa bibliografia $^{6}$ en defensa de la orden jesuita confirma su profunda admiración por ésta, influyendo seguramente en su sobrino y casi coétaneo, el padre Basilio Arrillaga, considerado como uno de los jesuitas más impor. tantes del siglo XIX, tanto por sus altos cargos eclesiásticos como por su presencia en los círculos políticos más representativos. Sobrino y tío compartieron muchas tareas; se sabe que Dávila ayudaba a Arrillaga a escribir libros y artículos, de ahí que la cercanía sea reconocible en recursos argumentativos, en tácticas defensivas, comunes y esperables en los miembros de la Compañía de Jesús, que aparecía y desaparecía de la escena nacional dejando siempre huellas inextinguibles.

En la pugna entre dos concepciones ideológicas y estéticas, Las breves observaciones... de Mariano Dávila

${ }^{6}$ Dávila, entre otras obras, es autor de la Continuación de la Compañia de Jesús en Nueva España, del padre Francisco Javier Alegre (1888); Defensa de la Compañía de Jesús (1842). Su intervención en el Diccionario de Historia y Geografia (1853) es notoria, pues se encargó de la parte eclesiástica y de los tres tomos del apéndice. 
constituyen una verdadera fuente para comprender y valorar varios aspectos: la recepción de la obra de Riva Palacio en el momento mismo de su publicación, el estatuto de la novela histórica $y$, por ende, el estado de cierta crítica literaria de entonces

\section{II}

A partir de la presunta ruptura de expectativas como lector de una novela que ha ofrecido respetar la historia -recordemos que Monja y casada... llevaba el subtítulo de Memorias de la Inquisición-, Mariano Dávila emprende dos polémicas, la histórica y la literaria, según su propia caracterización. En la primera realiza un minucioso cotejo de los sucesos históricos: la fundación del convento de Santa Teresa la Antigua; el tumulto de $1624, y$ algunos asuntos sobre el funcionamiento del tribunal del Santo Oficio. Riva Palacio es tachado de incipiente y arbitrario historiador, que trastoca la veracidad de los hechos para desprestigiar al clero mexicano. Las minuciosas aclaraciones y enmiendas del historiador Dávila podrían haber bastado para echar por tierra la novela, pero el éxito de ésta, comprobable en el agotamiento de las entregas, seguramente le incitó a la tarea de analizarla como obra de ficción.

Los parámetros a los que es sometida la novela indican la adhesión a una poética neoclásica europea, corriente en la segunda mitad del siglo XIX. Aunque Dávila menciona vagamente sus fuentes, aplica preceptos que ya habían remontado algunas de las ense- ñanzas dé Luzán en el mundo hispánico, pero que no aceptaban del todo la estética romántica. Dávila muestra un alto grado de actualización en cuanto al estado de la poética de la novela, ampliamente discutida durante todo el siglo XIX; es un lector avezado, que hurga para encontrar fallos y así descalificar, ejercicio propio de un dictaminador de libros para su censura, tarea que emprendió desde los primeros años de su vida sacerdotal.

La forma y el fondo de Monja y casada... constituyen los ejes del análisis; la primera ha de responder a lo bello, el segundo a lo bueno, inserto éste en la moralidad de la obra. En la belleza radican las cualidades reales $y$ verdaderas, que son la variedad, la unidad, la regularidad, el orden y la proporción, gobernadas por las siguientes reglas: la unidad de acción, la verosimilitud de los sucesos, la relación de los episodios y la moralidad del objeto. Las coordenadas, según se aprecia, corresponden al modelo neoclásico más corriente, por así decirlo.

La expresión de la belleza en la forma no pasa del todo el examen del crítico. La unidad y la variedad son aquí los conceptos clave. Según los preceptos de Manuel de la Revilla y Moreno, ${ }^{7}$ uno de los preceptistas espanoles de previsible influencia durante los años en que Dávila escribe su crítica, la unidad comprende un solo asunto, una sola idea, un solo plan, una sola inspiración. La variedad -elemento específico de la novela- comprende la acción expresada mediante episodios -muy numerosos-y los personajes.

${ }^{7}$ Revilla, Principios, 1877. 
Es la combinación de la unidad y la variedad la que logra una obra armónica, viva, es decir, bella. Monja y casada..., según Dávila, tiene varios asuntos, muchísimos episodios y, acaso lo más peculiar, asuntos o historias (usa indistintamente ambos términos) desconectados entre sí. Antes de profundizar en algunos ejemplos al respecto, conviene recordar brevemente la organización y el contenido de la obra y las condiciones de su recepción. La novela está dividida en cuatro libros, y cada uno en capítulos, ordenamiento al que se atiene Dávila; a esto hay que añadir la publicación por entregas, efecto que tiende a diluirse cuando, muy pronto, los fascículos integraron un volumen. A grandes rasgos las historias - efectivamente son varias-comienzan en el siguiente orden: la fundación del convento de Santa Teresa da pie a la primera historia sobre los amores-entre Beatriz de Ribera y el oidor Fernando Quesada. Intercalada en esa historia, aparece la de un esclavo, Teodoro, degradado en su pertenencia a la clase noble de su raza negra. Entre estas dos historias comienza a tejerse la historia central, cuyas protagonistas son dos mujeres: Luisa y Blanca Mejía, esta última la monja y casada, virgen y mártir, como se titula la novela. Henchida de sinuosidades, la historia central aparece y desaparece bajo el efecto de numerosas peripecias y de suspenso, impresos por un narrador que debe mantener las expectativas del lector que periódicamente recibe las entregas. En suma, Monja y casada... tiene una historia central y varias adyacentes.

Dávila, y acaso cualquier lector, espera que la primera historia enlazada a la fundación del convento de Santa Teresa la Antigua en 1615 sea la principal y la única, debido a su notable extensión. Este elemento, aunado a que el narrador recarga la crítica a las instituciones eclesiásticas, es materia de las más detalladas precisiones en cuanto a la verdad histórica. En el terreno literario, Dávila, al notar su progresiva desaparición, la considera un "ardid" para exhibir los desmanes del clero. Y es que, efectivamente, Riva Palacio pone de relieve el fanatismo religioso, rector de los destinos de las mujeres novohispanas; las argucias de las autoridades para apoderarse de bienes; lacras que seguramente los lectores de 1868 opondrían con facilidad a los efectos de las Leyes de Reforma. Atinadamente, Dávila advierte en la primera una especie de detonador de la historia central, aunque para él, consecuente con su perspectiva de análisis, la novela ya no obedece a un solo plan. Irá comprobando luego las dimensiones de los otros asuntos o historias en los que, además, observa títulos y subtítulos ajenos al contenido. No comenta, desde luego, que el narrador aumenta con ello el suspensoy, a la vez, mantiene un juego humoristico con el lector. Ejemplos: "Cómo 'en donde menos se piensa"; "Donde el 'diablo tira de la manta"'; "En que se sabe cosa increíble pero verdadera".

El juicio sobre el libro III, titulado "Monja y casada", ilustra la acuciocidad del crítico:

En efecto, aquí se verifican ambas condiciones. Pero tan al vapor, que más que asunto de un libro, cualquiera le 
diría episodio. Juzgándolo aritméticamente, hallaremos que de la página 293 a la 437 en que da principio el siguiente [...] por 144 fojas [...] apenas hay 29 en que se hace relación de su fuga del convento, de su matrimonio y aprehensión, pues aunque por todas son 41 , de las restantes tres se ocupan del Santo Oficio [...] otras tantas contiene el re. greso de Felisa y el sacristán, sus cóm. plices de fuga, al monasterio, y las restantes hacen poco a la historia. ${ }^{8}$

El señalamiento de la dilatación de secuencias es, sin embargo, advertido por el narrador:

Como dicen vulgarmente, que cuidados mayores quitan menores, por seguir el hilo de nuestra historia hemos abandonado desde hace mucho tiempo a dos personas que no por su poca representación dejan también, como dicen los modernos políticos, de haber contribuido con su "grano de arena".

Tal vez el lector no recuerde ya a Felisa, la muchacha del convento de Santa Teresa, y al sacristán su novio, a quienes abandonamos en los momentos mismos en que la ronda se cansaba en su persecución.

Los abandonamos en el momento del peligro, pero esto es en estos tiempos cosa muy común. ${ }^{9}$

Luego de esta salida humorística, trazando un movimiento inverso en la narración, se condensarán elementos clave del destino de una de las protagonistas de la historia central, como en preparación de un momento climático antecedente del desenlace. La rapidez con que se dan indicios defini-

"Dávila, Breves, 1869, p. 25.

9 Riva Palacio, Monja, 1982, vol. It, p. 167. tivos para entender el libro Iv indican nuevamente la dosificación del plan del narrador. No es ésta la opinión de Dávila, por supuesto; él sigue empeñado en perseguir una historia lineal, sin tantos vericuetos.

Respecto al comentario sobre la desrelación entre el título del libro III, "Monja y casada", con el contenido de sus 19 capítulos, es decir las " 144 fojas" ajenas a la historia central, constituye uno de los juicios más representativos de la argumentación de Dávila. Este dilatado espacio se inicia con una crónica sobre el estado socioeconómico de Nueva España en 1624, para introducir el segundo suceso histórico al ámbito novelesco: el gran tumulto de aquel año. Riva Palacio hace una doble conexión; por un lado con la fundación del convento de Santa Teresa, pues el entonces arzobispo Pérez de la Cerna se encargó de la adquisición de los terrenos para erigirlo y, de otro lado, con la historia central, porque nueve años más tarde, en 1624, el trámite de la dispensa de votos de Blanca Mejía, que le permite abandonar el convento, depende del mismo arzobispo. Dicho de otro modo, el autor eligió dos sucesos que ponen de relieve los excesos del arzobispo, que en 1624 , momento de efervescencia social, sostiene un acalorado pleito con el virrey marqués de Gelves; los dos protagonistas del suceso histórico ingresan a la historia ficticia central o, inversamente, como subraya Dávila, los personajes ficticios figuran en el suceso histórico. De ahí que diga:

Qué relación haya tenido este escandaloso acontecimiento con la novela his- 


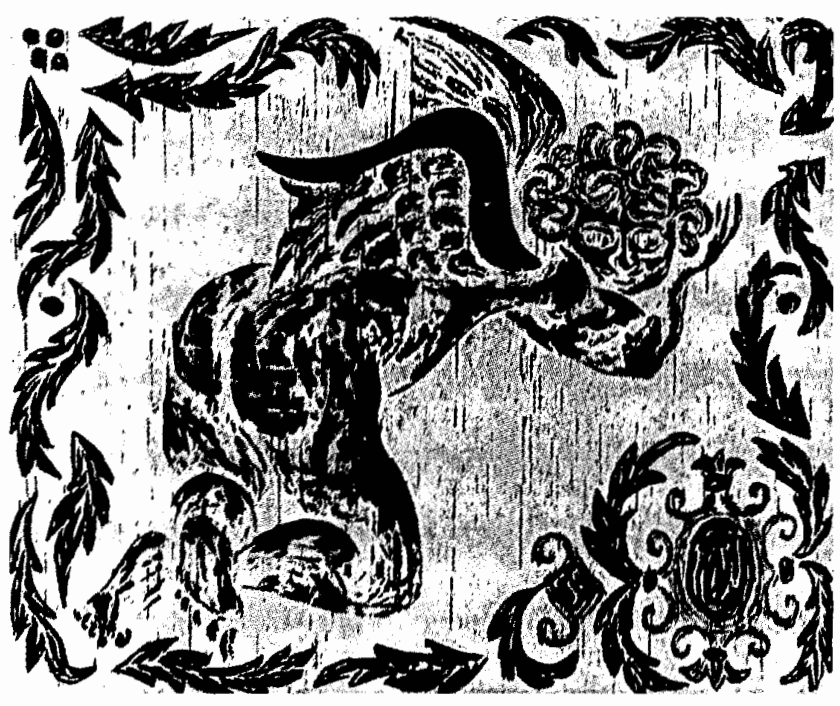

tórica de una monja, que aburrida de un estado, que si se quiere abrazó forzada por la tiranía y la codicia de su hermano, en desprecio de las censuras de la Iglesia, se fuga del claustro, se alza con un nombre supuesto y cae en consecuencia en poder de la Inquisición, tribunal en la época privativo para ésta y semejantes clases de delitos, nosotros no la alcanzamos a comprender; tanto más, cuanto que ese añejo y desfigurado episodio a nada conducía para el fin que se proponía el autor de dar a conocer una monja a la vez casada, y también virgen y mártir, ni hacia la menor falta para desenvolver cumplidamente su plan. Empero, desde el principio de la leyenda, algo se entrevió, por la narración del acto de posesión de las casas legadas para el convento de Santa Tere$\mathrm{sa}$, fuertemente disputadas por el heredero del fundador [...] Desde luego comprendimos el espíritu de la novela. Bajo aquel extraño título que se le daba para llamar la atención, nada menos se proponía -según la moda del siglozaherir al arzobispo Pérez de la Cerna y al clero mexicano de esos tiempos. ${ }^{10}$

Las últimas frases de Dávila muestran que está enfrentándose a una novela de tesis que sostiene una postura ideológica distinta de la suya; no obstante, para descalificarla se está valiendo de una preceptiva que definía la novela histórica con ingredientes de difícil ejecución. Aquí Dávila coincide de nuevo con la preceptiva de Revilla, quien precisa para este tipo de

${ }^{10}$ Dávila, Breves, 1869, p. 35. 
obra una combinatoria de dos acciones, la histórica y la ficticia. En estas dos vertientes el narrador debe unirlas indisolublemente sin faltar a la verdad histórica, ni siquiera a la verosimilitud; retratar con fidelidad y animación las costumbres, ideas, sentimientos de la época; idealizar y embellecer la acción histórica sin que falte a la verdad de los hechos; no desfigurar el verdadero carácter de los personajes históricos y, por último, identificar los personajes ficticios con el espíritu de la época. Semejante tarea rara vez se cumple, según acepta el propio Revilla. Al respecto cabe preguntarse ¿por qué se aboga por la inexistencia de la novela histórica cuando casi todo el siglo XIX está colmado de obras de ese tipo? La posible respuesta reside en la rigidez de las preceptivas. Sin duda, las novelas de Walter Scott son el paradigma de la novela histórica del siglo xIX; en ellas, la historiografia y la literatura constituyen vasos comunicantes. Chateaubriand y todos los historiadores románticos emulan al narrador de la novela, miran al pasado y lo narran no como fue, sino como hubiesen querido que fuese; como apunta el historiador Juan A. Ortega y Medina:

Historiadores como Chateaubriand, Agustín Thierry y, sobre todo, Amable Barante recurren a estas engañosas y rebuscadas recreaciones y cifran casi todo su interés en darnos una matizada y animada narración, en lugar de asegurar 1a verdad de ésta. Escriben para narrar, no para probar. Scribitur ad narrandum, non ad probandum, como lo aconsejara Quintiliano. La historia no tenía, por consiguiente, que analizar con frialdad, sino emocionar como la poesía, puesto que, a fin de cuentas, la verdad poética, como lo había proclamado Aristóteles, era superior a la verdad histórica. ${ }^{11}$

Puede notarse entonces que la verdad poética, la verosimilitud proveniente de la poética clásica, emparenta las novelas de Walter Scott con la historiografia romántica, en tanto que los neoclásicos como Revilla -y Dávilasolicitan al novelista no faltar a la verdad histórica, ni siquiera a la verosimilitud, ni idealizar y embellecer la acción histórica faltando a la verdad de los hechos, preceptos que intentan sobreponer la presunta verdad histórica sobre la ficción para contrarrestar la imaginación del novelista, del narrador romántico, insoportable para quie. nes sujetan la novela a reglas y modelos más bien virtuales; el mejor ejemplo es el empeño de Dávila por analizar Monjay casada... como él hubiera querido que fuese, y no como Riva Palacio la escribió.

En ese tenor, Dávila finge no advertir la intención de Riva Palacio al fusionar las acciones del tumulto de 1624 con las de las protagonistas de la historia central, mixtura que produce paralelos notables, como la dilatada secuencia en que Blanca Mejía sale del convento en busca del amor, al mismo tiempo que las minorías social y económicamente oprimidas se rebelan. Dávila omite el paralelo entre el aliento libertario individual de la protagonista, y el colectivo, unido a los presagios del fracaso:

${ }^{11}$ Prólogo a Prescott, Historia, 1970, p. XTV. 
La ciudad estaba en grandísima alarma. El arzobispo exigía que en las tablillas de las puertas de las iglesias estuviesen los nombres de los que él había excomulgado [...]

Cerraban los curas y los vicarios las puertas de las iglesias, e intervino entonces "el brazo secular" y se hacían abrir por fuerza, y esto con escándalo tan grande que ya nadie atendía a sus negocios ni a sus naturales ocupaciones, sino que andaban por todas partes inquiriendo noticias y tomando partido.

Así duraron las cosas todo el día [...]

A las oraciones de la noche, don César, Teodoro, su mujer y un anciano sacerdote llegaron a la casa en que vivía doña Blanca [...]

La joven esperaba ya con impaciencia, estaba vestida de blanco, y su belleza resaltaba más con aquel traje vaporoso sin adornos y sin alhajas [...]

Blanca, trémula y confusa, pronunció sus nuevos votos y la bendición del anciano sacerdote vagó sobre aquellas dos hermosas cabezas.

Blanca era por fin la esposa de don César de Villaclara.

Eran las ocho de la noche y repentinamente se escuchó a lo lejos el clamor triste de las campanas de la catedral, y luego el de todas las iglesias de la ciudad, que se elevaba en el silencio de la noche como un presagio sombríamente siniestro.

- ¿esús nos ampare! -exclamó el anciano religioso cayendo de rodillas.

- ¿Pues qué es eso, señor? -preguntô Blanca más pálida que un cadáver.

- La maldición de Dios sobre esta ciudad desgraciada -contestó el religioso-. Tocan entredicho.

-iEntredicho! -repitieron todos espantados.

-iJesús nos valga! -dijo Blanca desmayándose [...]
Las campanas seguían, tocaban pavorosamente a entredicho y el tumulto en las calles era espantoso. 12

Las omisiones de Dávila, conviene recordar, se relacionan con su rechazo a la hipérbole derivada del punto de vista del narrador, elemento central de la polémica histórica, donde el crítico muestra que Riva Palacio se sitúa en lo alto, a distancia, en vez de intentar ubicarse en el "teatro de los acontecimientos"; de ahí que el gran tumulto de 1624 aparezca como un suceso muy importante:

Un tumulto espantoso en aquella época [...] armado el pueblo contra la primera autoridad política [...] la eclesiástica arrastrada al destierro con el mayor vilipendio $\mathrm{y}$ atropellamiento $[\ldots]$ clamores sediciosos lanzados por la gente más desalmada y perdida de la sociedad [...] gritos, confusión, escalamientos, incendio, saqueos, amenazas, sangre y muertes [...] en una palabra, un motín terrible, alterando la paz pública y comprometiendo los intereses generales y particulares de una población, la primera de la Nueva España, su capital, su metrópoli [...] He aquí la horrible montaña distante de nosotros [...] y tan lejana como casi dos siglos y medio. Venzamos esta enorme distancia, sin declinar empero de la vía recta a las tortuosas; guiados por la razón y la crítica, no por la pasión y el espíritu de partido; por la verdad, no por la imaginación. ${ }^{13}$

Monjay casada... no posee la belleza formal que solicitan los preceptos neoclásicos; como cualquier románti-

${ }^{12}$ Monja, vol. II, pp. 110, 111, 112 y 113.

${ }^{3}$ Dávila, Breves, 1869, pp. 35-36. 
co, Riva Palacio imprime unidad a la acción y al conjunto pues, como sub. rayamos, la historia central atrae a las secundarias con movimientos sinuosos que abrevian, alargan o suspenden -recurso eficaz para mantener la expectativa de un lector que recibe las entregas-, para distender la emoción ante los destinos de personajes que se debaten en la pasión amorosa o en la opresión del fanatismo religioso, o en el intento de acceder a un mejor puesto en la sociedad virreinal, o siquiera mejorar lo que se tiene. El plan responde entonces a unos principios básicos de la narración, pero ésta se desarrolla mediante distintos recursos, sin reglas fijas, como decía Victor Hugo en relación con el drama, $y$ "según las condiciones propias de cada asunto". ${ }^{14}$ No puede haber belleza en la novela de Riva Palacio porque domina la asimetría, consecuente con las pasiones de los personajes y los movimientos de la sociedad novoshipana que él se empeña en contrastar con la de su presente. Son estos elementos los que despiertan la pasión combativa de Dávila, quien, contrario al "espíritu de partido", continuaba alargando sus Breves observaciones... sobre Monja y casada...

III

Una novela no es la historia, es verdad; pero un panorama tampoco es un verdadero paisaje, y sin embargo, si las reglas de la perspectiva no son bien observadas, si los árboles no estriban 20.

14 "Introducción Victor Hugo Cromwell", p. en el suelo, si los hombres son más grandes que las casas, si los caballos vuelan por el aire y las nubes se arrastran por la tierra, las gentes separarán los ojos con fastidio; porque el sentimiento de lo verdadero que tenemos en nosotros será ofendido, y porque el pintor habrá obrado en oposición a los principios del arte que debe imitar a la naturaleza. ${ }^{15}$

Este fragmento es citado por Dávila sin dar de su autor más que el dato significativo de haberse ocupado de El conde de Montecristo de Dumas; define el concepto de verosimilitud con el que se analizará Monja y casada..., es decir, esclarece un punto clave: el traslado de la realidad a la obra literaria, el centro, como sabemos, de las teorías estéticas y, por ende, de las poéticas. Copiar o imitar a la naturaleza son los términos de los que se desprenden distintos conceptos de verosimilitud. El fragmento citado señala que un panorama implica un recurso para trasladar un paisaje verdadero, proceso gobernado por el punto de vista del narrador y cuyo resultado final será la verdad artística, de modo tal que la realidad llevada a una novela no es la realidad de la historia; compete al narrador, sin embargo, imaginar o inventar, en su imitación de la naturale$\mathrm{za}$, lo que cabe o puede haber en ella, esto es, lo verosímil. Aquí estriba la cuidadosa tarea del novelista, o como recomienda Dávila a Riva Palacio: "Para mentir y comer pescado hay que tener mucho cuidado."

El fragmento citado toca el proble-

is Dávila, Breves, 1869, p. 43. 
ma del realismo en la novela, objeto de polémicas en Europa desde los años cuarenta del siglo XIX, con el surgimiento del folletín, hasta los ochenta, a propósito del naturalismo. En España, por ejemplo, menudeaban las críticas al realismo por cuanto que las obras pintaban vicios, miserias morales; se pedía, en cambio, fantasía, no ser fiel a la realidad. ${ }^{16}$ A fines de los años setenta, Revilla recomendaba no copiar servilmente a la naturaleza, sino "representarla con 'libre idealidad' [...] eligiendo en la realidad los objetos, rasgos y momentos más bellos, dejando en la sombra o usando como contraste lo feo"17. pues, subrayaba, "es innegable que la ficción artística es más bella que la realidad". ${ }^{18}$ Entonces ¿por qué a la novela histórica se le pide fidelidad a la verdad histórica? La respuesta obvia procede de las dos acciones que en ella aparecen y, siguiendo a Revilla, por la combinación de una doble verosimilitud, la histórica y la artística, que produciría un hipotético y peculiar realismo. Volviendo a la definición del preceptista español, resulta fácil notar un realismo discriminador que privilegia lo bello, evita lo feo, en precisa oposición a la estética romántica. ${ }^{19}$

La verosimilitud ocurre en la relación entre la obra y el lector; éste puede o no aceptar lo verdadero, de ahí que el concepto cambie según la época. El concepto neoclásico que Dávila aplica a Monja y casada... no resulta

16 Zavala, Texto, 1981.

17 Principios, 1877, p. 82.

18 Ibid., p. 78.

19 Víctor Hugo, Cromwell, 1977. pertinente por su índole romántica, que naturalmente produce otra verosimilitud; contra ésta, el crítico ofrece la veta más interesante de su análisis porque ahí discierne la moralidad de la novela.

Como se ha señalado varias veces, el desapego a la verdad histórica produce inverosimilitud en los personajes; Dávila señala la ausencia de virtud en ellos: todos poseen alguna mancha, sea el fanatismo religioso, sea la servidumbre del estado amoroso o bien los bajos intereses mundanos.

En otras palabras, Riva Palacio exhibe las miserias humanas. En la polémica histórica Dávila precisa el "verdadero" carácter de los personajes históricos; el arzobispo Pérez de la Cerna y el virrey marqués de Gelves son tergiversados en la novela para depositar en el primero el afán de poder y el consecuente uso de medios deshonestos y, en el segundo, un temple equilibrado para gobernar y apaciguar el afán de la máxima autoridad eclesiástica. Pero lo más insoportable para Dávila es que ambos personajes se mezclan con los de ficción, sobre todo con los de la más baja clase social. En efecto, el arzobispo se alía con delincuentes para ir en contra del virrey; así, Martín Garatuza, un maleante, aparece como lí. der de la multitud, durante el tumulto de 1624, junto con el Ahuizote, perteneciente también a lo peor de la sociedad y, como dice Dávila, ambos forman la "falange revolucionaria" del arzobispo.

Lo inverosímil reside en que se presentan como primeros actores no sólo ante el "populacho bárbaro e ignorante", sino ante el propio virrey; el resul- 


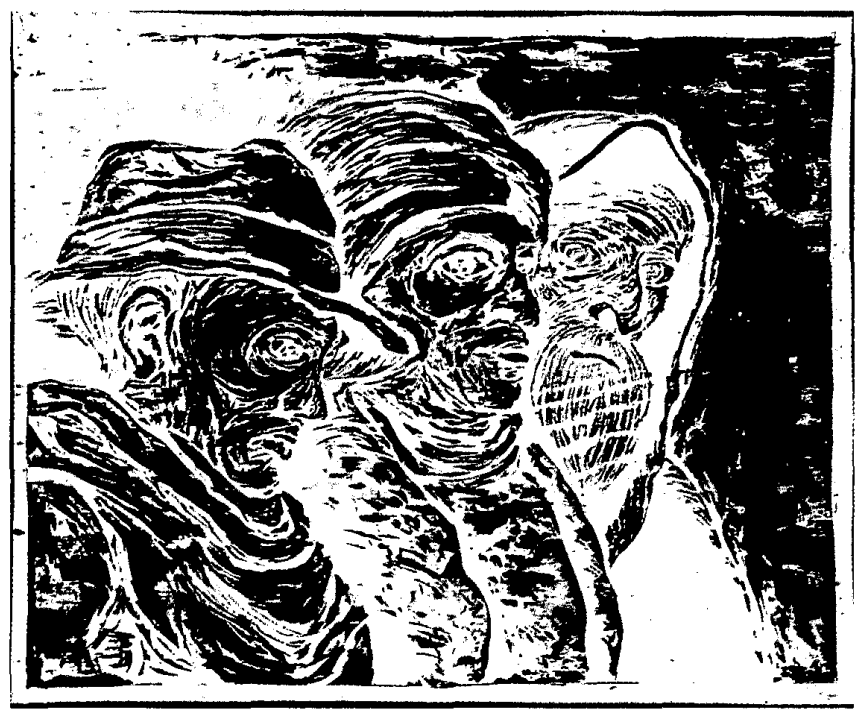

tado es un "lunar que afea" y no una escena creíble. Al respecto conviene notar que, en principio, Dávila está extremando su concepto de verosimilitud al señalar que esos personajes pueden ser creíbles, soportables a la ignorancia del populacho, pero no ante el virrey, más educado por supuesto. Existen pues grados, clases sociales en la verosimilitud. Y no le falta razón; la novela de Riva Palacio se dirigía a lectores diferentes a Dávila, que aceptaban, según se comprueba por el rápido agotamiento de las entregas de la novela, el intercambio y la fusión de papeles en la escala social. De ahí que el crítico endurezca más su defensa de la verosimilitud histórica, hasta el grado de rechazar cambios de indumentaria que puedan sugerir cambios de estrato social, como en el caso de el Ahuizote, presentado así en la novela:

Era un hombre de raza indígena pura, con su tez cobriza, su pelo negro y lacio, sin barba y con un escaso bigote.

Vestía una ropilla ordinaria de vellu. do, con calzón de escudero y unas medias calzas de venado; estaba envuelto en un tabardo gris y conservaba en su cabeza un sombrero de anchas alas. ${ }^{20}$

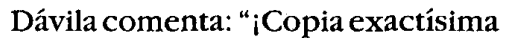
de un indio del siglo xvi! Pero si se sustituye al sombrerote la gorra de terciopelo negro con su pluma: ¿quién no diría ser el retrato de un paje del

${ }^{20}$ Monja, 1982, vol. 1, p. 77. 
mariscal Byron, o de Sancho Ortiz de Roelas?"21

Puede advertirse que las presuntas infracciones a la verosimilitud aluden a la subversión que del orden social propone el personaje romántico. Martín Garatuza y el Ahuizote ascienden mo mentáneamente -aunque, a la inversa, sus acciones se alarguen- en la escala social hasta la cúspide, hasta el lugar de las autoridades políticas y eclesiásticas de Nueva España y, en sentido inverso, el virrey y el arzobispo descienden y se alían a los representantes del más bajo estrato social. Esta ilusoria movilidad conmovería seguramente a los lectores de Monja y casada..., muy distantes ya del siglo xVII y, por ello, inmersos en un orden social distinto del colonial, que facilitaba aspiraciones de ascenso. Y como ya señalamos, es en la relación obra-lector donde se crea la verosimilitud; la aceptación del lector responde a su identificación con los personajes. Éstos le representan sus aspiraciones, sus fantasías, sus ilusiones, que se erigen en modelo y pueden ser emulables. Riva Palacio es, por tanto, un narrador romántico, y comotal resulta amenazante para cierto tipo de moral -la del fanatismo católico que impide la libertad de las mujeres novohispanas, y también de las decimonónicas-, que realza los afanes de libertad en los años tempranos de la colonia; que sin ningún recato exhibe la soberbia y la deshonestidad del arzobispo; que da toques de heroicidad a un delincuente $y$, en suma, escribe una novela de la que esperamos el dominio de la ficción, no obs-

21 Dávila, Breves, 1869, pp. 16-17. tante que aparece con el sospechoso subtítulo de Memorias de la Inquisición.

\section{IV}

La extensión, profundidad y sentido de Las breves observaciones sobre Monja y casada... contribuyen a verificar tanto algunos elementos del más extremo conservadurismo estético como la singularidad y, sobre todo, la eficacia de la novela de Riva Palacio, que logran avivar las ideas de los liberales y amenazar así los principios conservadores más furibundos.

La polémica del padre Dávila se dio entre algunas respuestas de Riva Pala. cio que conviene recordar. Desde los inicios de la publicación de Calvario $y$ Tabor, la primera novela de Riva Palacio, La Revista Universal, que mantenía posturas diferentes a las de $L a$ Orquesta y, por ende, a las ideas liberales, publicó los prospectos e informaba de las entregas; lo mismo ocurrió con Monjay casada... A propósito de la cuarta entrega, la "Gacetilla", firmada por J. J. Arriaga, decía:

Con gusto hemos notado que es el producto de serios estudios sobre los sucesos, las costumbres y el lenguaje de la época que describe, y que haciendo a un lado las exageraciones vulgares que tanto han desacreditado este género de literatura, excita con su bien combinada narración el más vivo interés de los lectores para conocer en todos sus detalles las aventuras de los personajes que figuran en su obra. ${ }^{22}$

${ }^{22}$ La Revista Universal, 27 junio 1868. 
A principios del mes de agosto de 1868, La Revista Universal publicaba un largo artículo sobre la Inquisición y Santo Domingo, acerca del cual hizo observaciones El Siglo XIX, a propósito del santo "tostador". La respuesta del primer periódico al segundo fue comentada en La Orquesta. Los redactores de La Revista Universal declaraban su propósito de tratar a la Inquisición desde un punto de vista histórico y con ello "combatir los errores de los nuevos moralistas buscadores de escenas horripilantes, para confeccionar dramas románticos". ${ }^{23} \mathrm{El}$ comentario se produce cuando ya había salido a la luz la quinta entrega de Monja y casada... La Orquesta tercia en la polémica de los periódicos antedichos y acepta la petición del periódico $E l$ Constitucional para dedicar al asunto un "Obligado" a la defensora de la Inquisición, en el que se lee una defensa de la novela:
Aunque sujetos a errores no buscan los buscadores asuntos edificantes, pues no es preciso buscar donde se pueden hallar como quien dice, al acaso, o mas bien a cada paso, en las pasadas edades, mil innegables verdades que según miro y contemplo, son cada una como un templo. ${ }^{24}$

Descubierta la identidad de Dávila, La Orquesta da respuestas humoristicas ante el desafio de otorgar pruebas:

23 La Orquesta, 8 agosto 1868.

${ }^{24}$ Loc. cit.
¿Qué podremos decir ante la severa y juiciosa crítica de nuestro amable presbítero...? La verdad, nada, porque sería preciso escribir un libro entero. La verdad es que nosotros estudiamos la historia por otro autor muy distinto del que se la enseñó al padre Dávila, y allá cada uno de los que han leído crítica y novela mediten, darán la razón al que la tenga, que esto es tan fácil, que a nadie le parecerá cosa del otro jueves. ${ }^{25}$

Así, mientras Mariano Dávila cotejaba fuentes y mostraba verdades para denostar a Riva Palacio, éste se burlaba de la embestida del presbítero, y más bien parecía advertir en las Breves observaciones la mejor propaganda para su novela, como se puede apreciar en el "Obligado" toque que La Orquesta dedica "Al gran perlado don Dávila por su crítica de la novela Monja y casada":

¿Qué nos movió buen perlado?

¿De dónde vos ocurrir fablar esa larga historia, e buscando el galardón que todos somos tenidos de dar a nuestro señor, facer injuria a los buenos con lo que nadie leyó e llamar breve reseña la cansada relación? que más valiera que leerla yogar un año de prisión, que más parecen denuestos a la santa religión, que defensa de perlado

Don Dávila, por favor, si non callades muy presto

${ }^{25}$ La Orquesta, 9 enero 1869. 


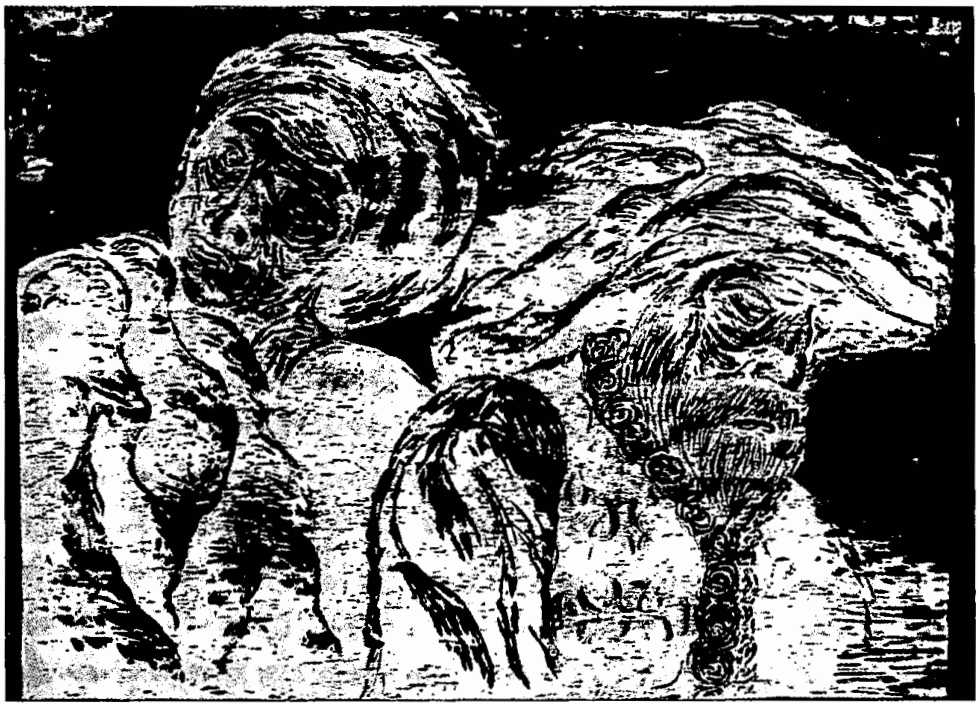

se acaba la suscripción, e le facéis grande tuerto al santo vuestro editor. ${ }^{26}$

Por su parte, La Revista Universal afirmaba: "Poco importa al público el nombre de los autores, y sí mucho el esclarecimiento de la verdad histórica." 27 En cierto desafio solicita a $L a$ Orquesta pruebas. Ésta comienza a dar respuestas un tanto elusivas -como que más tarde comprobará conductas revoltosas del arzobispo Pérez de la Cerna, personaje de la novela-, al lado de una muy precisa: todo cabe en el tejido de la fábula porque Monja $y$ casada... es una novela. Sobre esto, $L a$

26 Ibid., 23 enero 1869.

27 La Revista Universal, núm. 426.
Revista Universal puntualiza su opinión en los siguientes términos:

Nosotros estamos convencidos de que las novelas son un tejido de escenas fantásticas, inverosímiles, propias sólo para entretener a la gente incapaz de otras lecturas útiles y provechosas. $L a$ Orquesta ha confirmado más nuestra opinión [...] poniendo de manifiesto lo que se puede esperar de las que se apellidan históricas. ${ }^{28}$

Así, por la Navidad de 1868, Mariano Dávila y Vicente Riva Palacio, aunque el primero jamás lo nombra en su crítica y el segundo se escuda en el pseudónimo Juan de Jarras, mantienen una

${ }^{28}$ La Revista Universal, 21 diciembre 1868. 
polémica que los retrata de cuerpo entero: solemnidad versus sentido del humor.

Si las respuestas elusivas de Riva Palacio atienden a la actitud propia de un autor de novelas históricas, la desmesurada crítica de José Mariano Dávila descubre no sólo al censor de libros, sino a un hábil crítico que, en armonía con la publicación de la novela, decide polemizar por entregas y con ello obtenervarios y eficaces efectos: compite con la tarea de Riva Palacio que escribía las entregas de Martín Garatu$z a$, continuación de Monja y casada...; por tanto, le robaba público desprestigiándolo como novelista fallido según los cánones neoclásicos $\mathrm{y}$, desde luego, como pésimo historiador.

Mariano Dávila escribió sus Breves observaciones apenas un año antes de su muerte; ya octogenario y dando pruebas de su terrible combatividad, logró un recurso por demás singular: combatir al enemigo usando las armas de éste, y Vicente Riva Palacio, que con Monja y casada... iniciaba una serie de novelas sobre el pasado colonial, no pudo tener mejor prueba de su acierto: la novela es el mejor vehículo para transgredir la historia y presentar a los lectores de su tiempo un nuevo pasado colonial.

\section{BIBLIOGRAFIA}

-Alguien (pseudónimo del presbítero José Mariano Dávila), Breves observaciones sobre la moderna novela titulada "Mon- ja y Casada, virgen y mártir. (Historia de los tiempos de la Inquisición"). Aceptación de un tremebundo reto, Imprenta Literaria, México, 1869.

-Gutiérrez y Casillas, José, S.J., Jesuitas en México durante el siglo XIX, Porrúa, México, 1983.

-Ortiz Monasterio, José, Historia y ficción. Los dramas y novelas de Riva Palacio, Instituto Mora/Universidad Iberoamericana, México, 1994.

-Prescott, W. H., Historia de la conquista de México, prólogo de Juan A. Ortega y Medina, Porrúa, México, 1970.

-Revilla y Moreno, Manuel de la, Principios generales de la literatura e historia de la literatura española, 2a. ed. corregida y aumentada, vol. I, Librerías de F. I. Iravedra y A. Novo, Madrid, 1877.

-Riva Palacio, Vicente, Monja y casada, virgen y mártir, pról. de A. Castro Leal, Porrúa, México, 1982 (Colección Escritores Mexicanos, 18 y 19). Martín Garatuza, pról. de A. Castro Leal, Porrúa, México, 1975 (Colección Escritores Mexicanos, 20 y 21). Calvario y Tabor, Manuel C. Villegas y Compañía, México, 1868, ils. de Constantino Escalante.

- Víctor Hugo, Cromwell. Drama en cinco actos, Editores Mexicanos Unidos, México, 1977 (Colección Literaria Universal).

-Zavala, Iris, El texto en la historia, Nuestra Cultura, Madrid, 1981.

\section{HEMEROGRAFÍA}

-La Orquesta, Periódico Omniscio, de Buen Humor y con Caricaturas, México, 1868 y 1869.

-La Revista Universal, periódico, 1868 y 1869. 